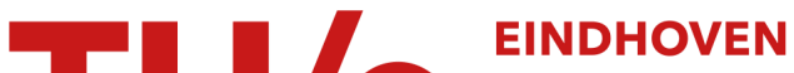 UNIVERSITY OF TECHNOLOGY
}

\section{Formation of columnar (In,Ga)As quantum dots on $\mathrm{GaAs}(100)$}

\section{Citation for published version (APA):}

He, J., Nötzel, R., Offermans, P., Koenraad, P. M., Gong, Q., Hamhuis, G. J., Eijkemans, T. J., \& Wolter, J. H. (2004). Formation of columnar (In,Ga)As quantum dots on GaAs(100). Applied Physics Letters, 85(14), 27712773. https://doi.org/10.1063/1.1801172

DOI:

10.1063/1.1801172

Document status and date:

Published: 01/01/2004

\section{Document Version:}

Publisher's PDF, also known as Version of Record (includes final page, issue and volume numbers)

\section{Please check the document version of this publication:}

- A submitted manuscript is the version of the article upon submission and before peer-review. There can be important differences between the submitted version and the official published version of record. People interested in the research are advised to contact the author for the final version of the publication, or visit the $\mathrm{DOI}$ to the publisher's website.

- The final author version and the galley proof are versions of the publication after peer review.

- The final published version features the final layout of the paper including the volume, issue and page numbers.

Link to publication

\section{General rights}

Copyright and moral rights for the publications made accessible in the public portal are retained by the authors and/or other copyright owners and it is a condition of accessing publications that users recognise and abide by the legal requirements associated with these rights.

- Users may download and print one copy of any publication from the public portal for the purpose of private study or research.

- You may not further distribute the material or use it for any profit-making activity or commercial gain

- You may freely distribute the URL identifying the publication in the public portal.

If the publication is distributed under the terms of Article 25fa of the Dutch Copyright Act, indicated by the "Taverne" license above, please follow below link for the End User Agreement:

www.tue.nl/taverne

Take down policy

If you believe that this document breaches copyright please contact us at:

openaccess@tue.nl

providing details and we will investigate your claim. 


\title{
Formation of columnar (In,Ga)As quantum dots on $\mathrm{GaAs}(100)$
}

\author{
J. He, ${ }^{\text {a) }}$ R. Nötzel, P. Offermans, P. M. Koenraad, Q. Gong, G. J. Hamhuis, \\ T. J. Eijkemans, and J. H. Wolter \\ eiTT/COBRA Inter-University Research Institute, Eindhoven University of Technology, \\ $5600 \mathrm{MB}$ Eindhoven, The Netherlands
}

(Received 28 April 2004; accepted 10 August 2004)

Columnar (In,Ga)As quantum dots (QDs) with homogeneous composition and shape in the growth direction are realized by molecular-beam epitaxy on $\mathrm{GaAs}(100)$ substrates. The columnar (In,Ga)As QDs are formed on InAs seed QDs by alternating deposition of thin GaAs intermediate layers and monolayers of InAs with extended growth interruptions after each layer. The height of the columnar $(\mathrm{In}, \mathrm{Ga})$ As QDs is controlled by varying the number of stacked GaAs/InAs layers. The structural and optical properties are studied by cross-sectional scanning tunneling microscopy, atomic force microscopy, and photoluminescence spectroscopy. With increase of the aspect ratio of the columnar QDs, the emission wavelength is redshifted and the linewidth is reduced. () 2004 American Institute of Physics. [DOI: 10.1063/1.1801172]

Quantum dots (QDs) have attracted considerable interest as they exhibit unique optoelectronic properties. ${ }^{1-3}$ One of the most widely investigated methods for QD fabrication is self-assembly in the Stranski-Krastanov (SK) growth mode in the epitaxy of lattice mismatched systems. For the most common growth conditions for InAs on GaAs(100) these QDs typically emit around $1 \mu \mathrm{m}$ with a linewidth of several tens of milli-electron-volts. To tune the electronic properties of the QDs with respect to, e.g., emission wavelength, subband energy spacing, lateral confinement energy, and polarization behavior, various approaches have been pursued. These include QD stacking, reduction of the growth rate, and interrupted growth to control the effective QD size and shape; and the overgrowth by strain reducing (In, Ga)As and (In,Al)As layers. ${ }^{4-8}$ We have recently introduced leveling and rebuilding of InAs QDs on GaAs(100) substrates during molecular beam epitaxy (MBE) of multiple ultrathin GaAs/InAs overlayers which drastically improves the QD size uniformity and optical properties due to the exchange of InAs between neighboring QDs. ${ }^{9}$

Here we report leveling and rebuilding as an effective route for the creation of height controlled columnar (In, Ga)As QDs. The introduction of extended growth interruptions after alternating deposition of the thin GaAs and InAs layers on InAs seed QDs produces columnar (In, Ga)As QDs which are uniform both in composition and shape in the growth direction, and whose height is directly determined by the number of stacked GaAs/InAs layers. The photoluminescence (PL) emission wavelength of the columnar QDs is systematically redshifted with increase of the height, i.e., aspect ratio, which is accompanied by a reduction of the PL line width.

The samples were grown by solid source MBE on $\operatorname{GaAs}(100)$ substrates. After native oxide desorption at $580^{\circ} \mathrm{C}$, a 200 -nm-thick GaAs buffer layer was deposited. The substrate temperature was then lowered to $500^{\circ} \mathrm{C}$ for growth of 2 monolayers (ML) InAs forming the seed QD layer. For formation of the columnar QDs, $2 \mathrm{~nm}$ GaAs inter-

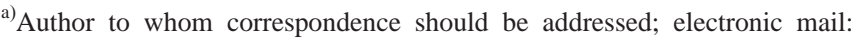
j.he@tue.nl mediate layers followed by 1 ML InAs were overgrown alternately on the InAs seed QDs with 90 s growth interruption after both the GaAs and InAs layers. The number of stacked GaAs/InAs layers was 0 for reference, 4 , and 8 . The growth rates of GaAs and InAs were 0.18 and $0.015 \mathrm{~nm} / \mathrm{s}$ and the $\mathrm{As}_{4}$ beam equivalent pressure was $1 \times 10^{-5}$ Torr. During growth, the QD evolution was monitored by reflection highenergy electron diffraction (RHEED). The structural and optical properties of the QDs were investigated by crosssectional scanning tunneling microscopy (X-STM), atomic force microscopy (AFM), and PL spectroscopy. The QDs investigated by X-STM and PL were additionally capped by a 5 - nm-thick $\operatorname{In}_{0.2} \mathrm{Ga}_{0.8}$ As strain reducing layer and $100 \mathrm{~nm}$ GaAs. The X-STM measurements were performed on (110) cleavage planes in ultrahigh vacuum in constant current mode. The PL was excited by the $532 \mathrm{~nm}$ line of a Nd:YAG laser with excitation power density of $256 \mathrm{~mW} / \mathrm{cm}^{2}$, dispersed by a single monochromator, and detected by a cooled InGaAs charge coupled device with the samples in a cryostat at $5 \mathrm{~K}$. The surface morphology of uncapped QDs was characterized in air by tapping mode AFM.

Figures 1(a) and 1(b) show the X-STM images of the columnar (In,Ga)As QDs with eight stacked GaAs/InAs layers overgrown by $5 \mathrm{~nm} \operatorname{In}_{0.2} \mathrm{Ga}_{0.8}$ As. The height contrast, in



(a)

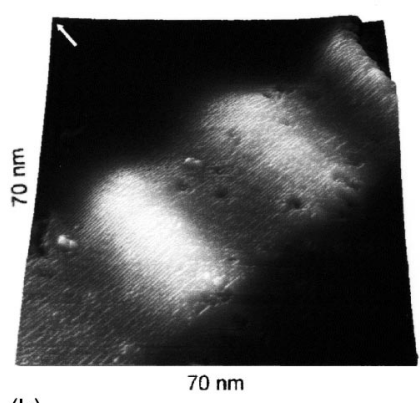

(b)
FIG. 1. (a) X-STM image of the columnar (In,Ga)As QD formed by eight stacked $2 \mathrm{~nm}$ GaAs/1 ML InAs layers on the $2 \mathrm{ML}$ InAs seed QD and overgrown by $5 \mathrm{~nm} \operatorname{In}_{0.2} \mathrm{Ga}_{0.8} \mathrm{As}$ on $\mathrm{GaAs}(100)$ substrate. The black arrows indicate the GaAs/InAs periods. (b) Three-dimensional image with enlarged scale. The white arrows indicate the growth direction. 


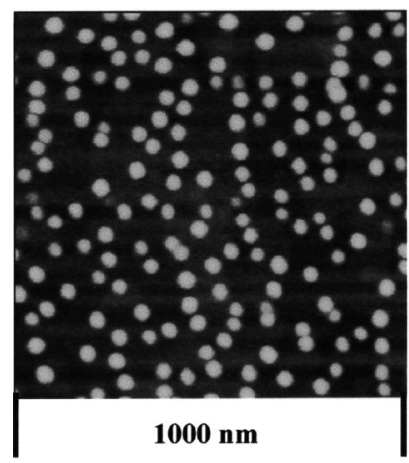

(a)

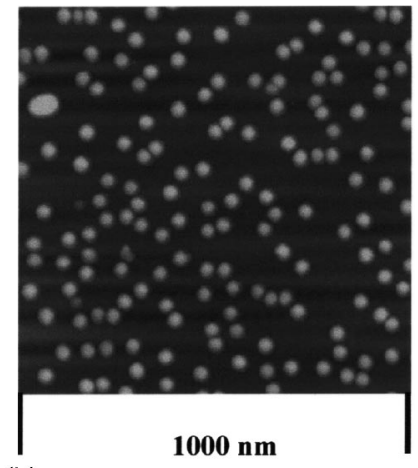

(b)
FIG. 2. (a) AFM image of the 2 ML InAs seed QDs on GaAs(100) and (b) of the columnar (In,Ga)As QDs formed by four stacked $2 \mathrm{~nm}$ GaAs/1 ML InAs layers on the $2 \mathrm{ML}$ InAs seed QDs. The scan field is $1000 \mathrm{~nm}$ $\times 1000 \mathrm{~nm}$ and the black-to-white height contrast is $8 \mathrm{~nm}$ in both images.

addition to the contrast from the bilayer atomic corrugation, originates from the outward bending of the compressively strained (In, Ga)As structure at the cleavage plane which is directly related to the In composition. ${ }^{10}$ The columnar QDs are vertical, confirming the strain correlated QD leveling and rebuilding during GaAs/InAs mutilayer growth. Most important, the In composition in growth direction is uniform within the detection limit of at most $5 \%$ variation within each period, as indicated by the black arrows in Fig. 1(a), and verified for a number of QDs [see also Fig. 1(b)]. The height of the QDs is $21 \mathrm{~nm}$, excluding the upper $5 \mathrm{~nm}$ $\mathrm{In}_{0.2} \mathrm{Ga}_{0.8} \mathrm{As}$ layer, which markedly exceeds that of QDs grown in the SK mode. Moreover, the QD height is substantially increased by the upper $\operatorname{In}_{0.2} \mathrm{Ga}_{0.8}$ As layer, which is attributed to strain driven In migration, ${ }^{9} 11$ i.e., In enrichment toward the top of the underlying columnar QD structure. Hence, the upper $\operatorname{In}_{0.2} \mathrm{Ga}_{0.8}$ As layer not only acts as the commonly described strain reducing layer but directly contributes to the QD height increase with the enlarged In composition only slightly lower than that of the columnar QDs beneath.

To confirm the uniformity in shape (diameter) of the columnar QDs in the growth direction, AFM measurements are compared of the surface of the $2 \mathrm{ML}$ InAs seed QDs [Fig. 2(a)] and that of the columnar (In,Ga)As QDs after $4 \mathrm{GaAs} / \mathrm{InAs}$ periods [Fig. 2(b)]. The density of the InAs seed QDs and of the columnar (In,Ga)As QDs is almost the same, indicating perfectly strain correlated growth in the build up of the columns. The lateral size of the InAs seed QDs of $41 \mathrm{~nm}$ is slightly larger than that of the columnar (In,Ga)As QDs of about $35 \mathrm{~nm}$. This is consistent with the results of X-STM in Fig. 1(a) revealing a slightly larger diameter at the bottom, which quickly adjusts to that of the QD column. Hence, the height of the columnar QDs is increased by repetition of the thin $\mathrm{GaAs} / \mathrm{InAs}$ layers and (In,Ga)As overgrowth, maintaining a uniform In composition and shape in growth direction. The lateral size distribution within the ensemble of the columnar (In,Ga)As QDs, however, remains comparable to that of the seed InAs QDs for the present layer sequence.

The formation of the columnar QDs involves a large amount of mass transport, which is allowed for by the introduction of extended growth interruptions. This is supported by the RHEED observations during deposition of the GaAs/InAs layers on the InAs seed QDs. After growth of the Downloaded 12 Nov 2007 to 131.155.108.71. Redistribution subject

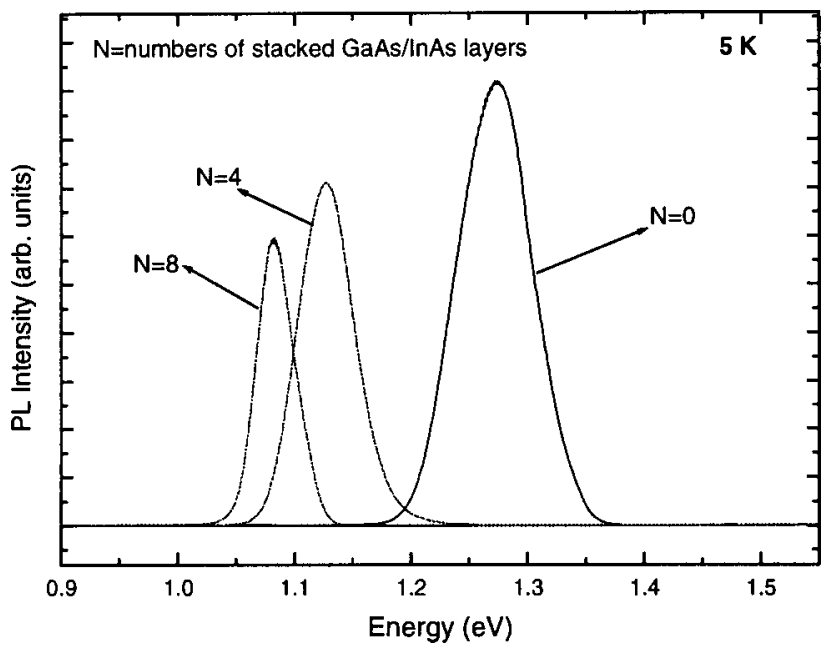

FIG. 3. PL spectra taken at $5 \mathrm{~K}$ of the columnar (In,Ga)As QDs formed by four and eight stacked $2 \mathrm{~nm} \mathrm{GaAs} / 1 \mathrm{ML}$ InAs layers on the $2 \mathrm{ML}$ InAs seed QDs and overgrown by $5 \mathrm{~nm} \operatorname{In}_{0.2} \mathrm{Ga}_{0.8} \mathrm{As}$ on $\mathrm{GaAs}(100)$. The PL from the InAs seed QDs (0 stacked layers) is shown for reference.

InAs seed QDs, characteristic chevrons are observed along the [0-11] direction. During deposition of the GaAs intermediate layer and following growth interruption, the chevrons evolve into short, streaky diffraction rods, due to leveling of the QDs. ${ }^{9,12}$ When the subsequent InAs layer is grown, the RHEED pattern changes back and during growth interruption clear chevrons develop, which indicate rebuilding of InAs QDs. The critical thickness for InAs QD rebuilding is 0.9 ML, which is much smaller than that of 1.7 ML for formation of the seed QDs.

Based on the structural characterization by X-STM, AFM, and RHEED, the formation of the columnar (In, Ga)As QDs is described as follows. When the thin GaAs layer is grown on the InAs QDs, Ga adatoms are driven away from the QDs due to the lattice mismatch, ${ }^{11,13}$ leaving the top of the QDs partially uncovered. During the growth interruption it is then energetically favorable for In atoms to detach from the QD top to form a partial wetting layer on the GaAs surface $^{11,13}$ together with segregated In atoms from the previous InAs layer. The presence of the partial wetting layer is confirmed by the fact that the critical layer thickness for InAs QD rebuilding during growth of the columnar QDs is much smaller than that for formation of the first InAs seed QDs. The detachment of In atoms from the QD top and the subsequent QD rebuilding and GaAs overgrowth are accompanied by strong $\mathrm{Ga}$-In intermixing driven by the reduction of the lattice mismatch. ${ }^{12}$ This together with the introduction of growth interruptions leads to the observed uniform In composition within the columnar QDs as well as the uniform low In composition in the areas between them, seen in Fig. 1(b).

Figure 3 depicts the PL spectra taken at $5 \mathrm{~K}$ of the columnar (In,Ga)As QDs with four and eight stacked GaAs/InAs layers together with that of the InAs seed QDs for reference. The PL of the columnar (In,Ga)As QDs is systematically redshifted with increase of the number of GaAs/InAs layers, i.e., of the QD aspect ratio, up to $190 \mathrm{meV}$ for the QDs with $8 \mathrm{GaAs} /$ InAs layers. The redshift is accompanied by a decrease of the PL linewidth from $57 \mathrm{meV}$ for the InAs seed QDs to $28 \mathrm{meV}$ for the eightperiod (In,Ga)As columnar QDs. This reduction of the PL linewidth is attributed mainly to the reduced influence of to AIP license or copyright, see http://apl.aip.org/apl/copyright.jsp 
vertical size fluctuations for QDs with increased height. ${ }^{14}$

In conclusion, by repeating thin GaAs intermediate layers between monolayers of InAs and the introduction of extended growth interruptions, homogeneous columnar (In, Ga)As QDs both in composition and shape in the growth direction have been fabricated on InAs seed QDs by molecular-beam epitaxy on GaAs(100) substrates. The height of columnar (In,Ga)As QDs has been controlled by varying the number of stacked GaAs/InAs layers, leading to a continuous redshift of the photoluminescence emission accompanied by a decrease of the linewidth.

${ }^{1}$ P. B. Joyce, T. J. Krzyzewski, G. R. Bell, and T. S. Jones, Appl. Phys. Lett. 79, 3615 (2001).

${ }^{2}$ K. Mukai, Y. Nakata, K. Otsubo, M. Sugawara, N. Yokoyama, and H. Ishikawa, IEEE Photonics Technol. Lett. 11, 1205 (1999)

${ }^{3}$ M. A. Migliorato, L. R. Wilson, D. J. Mowbray, M. S. Skolnick, M. Al-Khafaji, A. G. Cullis, and M. Hopkinson, Appl. Phys. Lett. 90, 6374 (2001).
${ }^{4}$ Y. Nakata, K. Mukai, M. Sugawara, K. Ohtsubo, H. Ishikawa, and N. Yokoyama, J. Cryst. Growth 208, 93 (2000).

${ }^{5}$ T. Kita, O. Wada, H. Ebe, Y. Nakata, and M. Sugawara, Jpn. J. Appl. Phys., Part 2 41, L1143 (2002).

${ }^{6}$ M. J. da Silva, A. A. Quivy, S. Martini, T. E. Lamas, E. C. F. da Silva, and J. R. Leite, Appl. Phys. Lett. 82, 2646 (2003).

${ }^{7}$ Y. Q. Wei, S. M. Wang, F. Ferdos, J. Vukusic, and A. Larsson, Appl. Phys. Lett. 81, 1621 (2001).

${ }^{8}$ S. Fafard, M. Spanner, J. P. McCaffrey, and Z. R. Wasilewski, Appl. Phys. Lett. 76, 2268 (2000).

${ }^{9}$ Q. Gong, R. Nötzel, G. J. Hamhuis, T. J. Eijkemans, and J. H. Wolter, Appl. Phys. Lett. 81, 1887 (2002).

${ }^{10}$ D. M. Bruls, J. W. A. M. Vugs, P. M. Koenraad, H. W. M. Salemink, and J. H. Wolter, Appl. Phys. Lett. 81, 1708 (2002).

${ }^{11}$ Q. Xie, P. Chen, and A. Madhukar, Appl. Phys. Lett. 65, 2051 (1994).

${ }^{12}$ P. B. Joyce, T. J. Krzyzewski, P. H. Steane, G. R. Bell, J. H. Neave, and T. S. Jones, Surf. Sci. 492, 345 (2001).

${ }^{13}$ K. Shiramine, S. Muto, T. Shibayama, H. Takahashi, T. Kozaki, S. Sato, Y. Nakata, and N. Yokoyama, J. Vac. Sci. Technol. B 21, 2054 (2003).

${ }^{14}$ K. Nishi, H. Saito, S. Sugou, and J. S. Lee, Appl. Phys. Lett. 74, 1111 (1999). 